\title{
Evaluation of Bone Turnover / Quality Markers and Bone Mineral Density in Prostate Cancer Patients Receiving Androgen Deprivation Therapy with or without Denosumab
}

\author{
YOSHIYUKI MIYAZAWA, YOSHITAKA SEKINE, TAKAHIRO SYUTO, MASASHI NOMURA, \\ HIDEKAZU KOIKE, HIROSHI MATSUI, YASUHIRO SHIBATA, KAZUTO ITO and KAZUHIRO SUZUKI \\ Department of Urology, Gunma University Graduate School of Medicine, Maebashi, Japan
}

\begin{abstract}
Background/Aim: Androgen deprivation therapy $(A D T)$ is a mainstay therapy for prostate cancer (PCa). ADT induces bone loss and increases the risk of osteoporosis and fractures. Recently, loss of bone quality has received attention as a factor that causes loss of bone strength independent of bone mineral density (BMD). Pentosidine has been identified as a surrogate marker of bone quality. Therefore, bone quality markers were evaluated retrospectively in PCa patients receiving ADT with or without denosumab. Patients and Methods: This study included 46 PCa patients. Twenty patients received denosumab. We measured pentosidine as bone quality marker and TRACP-5b as bone turnover marker. Pre- and 12month BMD was measured in the lumbar spine and femoral neck. Results: In the denosumab group $(D+), B M D$ at the lumbar spine was increased by $6.7 \%$ compared with the group that did not receive denosumab ( $D-)$ at 12 months $(p=0.0015)$. $B M D$ at the femoral neck was increased by $3.1 \%$ at 12 months $(p=0.0076)$. The mean value of TRAP-5b was lower in the D+ group than the $D-$ group at 12 months $(p<0.001)$. The mean serum levels of pentosidine in the $D+$ group were decreased by $-39.6 \%$ compared with the D- group at 12 months ( $p=0.0036)$. Conclusion: Denosumab increased BMD during $A D T$ for PCa and inhibited the increasing levels of serum pentosidine in PCa patients undergoing ADT.
\end{abstract}

Prostate cancer (PCa) is the most common cancer in males in Western countries and its incidence has increased in Japan (1). Androgen deprivation therapy (ADT) with gonadotropin-

This article is freely accessible online.

Correspondence to: Yoshiyuki Miyazawa, Department of Urology, Gunma University Graduate School of Medicine, 3-9-22 Showamachi, Maebashi, Gunma 371-8511, Japan. Tel: +81 272208306, Fax: +81 272208307, e-mail: miya.yoshi@hotmail.co.jp

Key Words: Prostate cancer, denosumab, bone quality, pentosidine. releasing hormone (GnRH) agonists, GnRH antagonists or bilateral orchiectomy is a well-established treatment for advanced PCa (2). ADT is also used to manage cases of localized PCa when radical treatment cannot be administered (3). The administration of ADT improves disease-free survival and overall survival in men with locally advanced PCa treated with radiation therapy (4). ADT functions by decreasing testosterone to castrate levels. ADT also markedly decreases serum estradiol levels because estradiol is derived from the peripheral conversion of testosterone by aromatase, also called estrogen synthase. Therefore, side-effects associated with estrogen deficiency are also observed. Estradiol plays a role in bone formation and bone resorption in men (5). Therefore, ADT decreases bone mineral density (BMD) and increases the incidence of clinical fractures (6, 7). The risk of fracture increases with an increasing duration of $\operatorname{ADT}(6,7)$. Patients with prostate carcinoma bone metastases are faced with the risk of skeletal complications, including pathologic fractures, which are collectively termed skeletal-related events (SREs) (8). SREs are associated with mortality, increased pain, decreased quality of life and increased treatment costs (9).

Although several drugs, including bisphosphonates and selective estrogen-receptor modulators, can prevent a decreased BMD, clinical trials of those drugs have revealed that the effects on fracture prevention are insufficient (10, 11). In contrast, denosumab was found to increase BMD at all sites and decrease the incidence of new vertebral fractures among men receiving ADT for non-metastatic PCa (12). Furthermore, denosumab decreased the risk of skeletal complications compared to zoledronic acid in castrationresistant prostate cancer (CRPC) patients with bone metastases (13). The administration of denosumab decreased the serum levels of bone turnover markers (BTMs), including type-1 C-teropeptide (sCTX) and tartrate-resistant alkaline phosphatase 5b (TRAP-5b) compared to placebo (14). Therefore, BTMs are often used to predict the effects of denosumab during CRPC patient care. 
Table I. Clinical characteristics of all patients.

\begin{tabular}{|c|c|c|c|c|}
\hline Characteristics & All & Denosumab (-) & Denosumab (+) & \\
\hline No. of patients & 46 & 26 & 20 & \\
\hline Age $($ mean \pm S.D. $)$ & $73.8 \pm 7.0$ & $74.6 \pm 5.9$ & $72.1 \pm 8.0$ & $p=0.239$ \\
\hline Initial PSA (median \pm S.D.) & $11.0 \pm 494.1$ & $9.59 \pm 55.0$ & $12.7 \pm 735.4$ & $p=0.129$ \\
\hline \multicolumn{5}{|l|}{ Stage } \\
\hline T1cN0M0 & 9 & 4 & 5 & \\
\hline T2N0M0 & 14 & 11 & 3 & \\
\hline T3N0M0 & 8 & 6 & 2 & \\
\hline T4NOM0 & 2 & 1 & 1 & \\
\hline TanyN1M0 & 3 & 2 & 1 & \\
\hline TanyNOM1 & 5 & 1 & 4 & \\
\hline TanyN1M1 & 5 & 1 & 4 & \\
\hline \multicolumn{5}{|l|}{ Metastasis } \\
\hline All distant metastasis & 10 & 2 & 8 & \\
\hline Bone metastasis & 7 & 1 & 6 & \\
\hline Visceral metastasis & 3 & 1 & 2 & \\
\hline \multicolumn{5}{|l|}{ Gleason score } \\
\hline GS 6 & 6 & 6 & 0 & \\
\hline GS 7 & 12 & 5 & 7 & \\
\hline $\mathrm{GS} \geq 8$ & 28 & 15 & 13 & \\
\hline BMD of lumbar spine $\left(\mathrm{g} / \mathrm{cm}^{3}\right)$ & $1.026 \pm 0.249$ & $1.064 \pm 0.181$ & $0.982 \pm 0.321$ & $p=0.198$ \\
\hline BMD of femoral neck $\left(\mathrm{g} / \mathrm{cm}^{3}\right)$ & $0.699 \pm 0.098$ & $0.731 \pm 0.106$ & $0.671 \pm 0.094$ & $p=0.044$ \\
\hline
\end{tabular}

S.D., Standard deviation; PSA, prostate-specific antigen; BMD, bone mineral density.

Bone strength is determined by BMD and bone quality (15). The bone matrix consists of a two-phase composite material in which the mineral phase provides stiffness and collagen fibers provide tensile strength. Collagen crosslinking plays important roles in the biological and biomechanical features of bone. Serum or urine pentosidine, a non-enzymatic collagen cross-linking element, and homocysteine levels are used to estimate the future fracture risk in osteoporosis $(16,17)$.

In the current study, bone quality markers, BTMs and BMD were evaluated retrospectively in $\mathrm{PCa}$ patients receiving ADT with or without denosumab.

\section{Patients and Methods}

Patients. This study included 46 patients with histologically confirmed PCa who were diagnosed at Gunma University Hospital (Maebashi, Japan) and evaluated retrospectively. Table I lists the clinical characteristics of the enrolled patients. Patients' ages ranged from $60-$ 87 years with a mean of 73.8 years. The clinical stage was T1cN0M0 in nine, T2NOM0 in 14, T3NOM0 in eight, T4NOM0 in two, TanyN1M0 in three, TanyN0M1 in five and TanyN1M1 in five patients. Ten patients had metastasis of which seven had bone and three visceral metastases. All patients received a monthly subcutaneous injection of degarelix ( $240 \mathrm{mg}$ for the first month followed by maintenance doses of $80 \mathrm{mg}$ ). Four patients were treated with bicalutamide as part of a combined anti-androgen blockade. We administered denosumab for patients who had bone metastasis or were diagnosed with osteoporosis at baseline. Twenty patients received denosumab (the D+ group): 16 of them received $60 \mathrm{mg}$ every 6 months (Pralia ${ }^{\circledR}$; Daiichi-Sankyo, Tokyo, Japan) to treat osteoporosis and prevent loss of BMD, while four received $120 \mathrm{mg} / \mathrm{month}$ (Ranmark ${ }^{\circledR}$; Daiichi-Sankyo) to treat bone metastasis. The Institutional Review Board of the Gunma University Hospital approved this study and written consent was obtained from all enrolled patients.

Measurement of BMD. BMD was measured in the lumbar spine and femoral neck at baseline and after 12 months using dual X-ray absorptiometry with the Horizon DXA system (Hologic, Marlborough, MA USA). Bone metastasis was not observed at the measured site in all patients.

Blood samples and measurement of bone turnover and quality markers. Baseline blood samples were collected from all patients, whereas post-treatment samples were taken after 6 and 12 months of treatment. Serum was stored at $-80^{\circ} \mathrm{C}$ until measurements. BTM and bone quality markers were assessed by SRL Inc. (Tokyo, Japan). TRACP-5b was measured using enzyme immunoassays (EIAs) and pentosidine was measured using enzyme-linked immunosorbent assays (ELISAs).

Statistical analysis. Values are expressed as means \pm standard deviations and were compared using Student's $t$-tests. A $p$-value $<0.05$ was considered significant. Analysis of variance (ANOVA) and the Tukey-Kramer method were used to analyze changes in bone markers between pretreatment and the other time points. 
Table II. Changes in BMD and bone turnover and quality markers.

\begin{tabular}{|c|c|c|c|c|}
\hline & \multicolumn{2}{|c|}{$\begin{array}{l}\text { Denosumab }(-) \\
\quad(\mathrm{n}=26)\end{array}$} & \multicolumn{2}{|c|}{$\begin{array}{l}\text { Denosumab }(+) \\
\quad(\mathrm{n}=20)\end{array}$} \\
\hline & \multicolumn{4}{|c|}{$\begin{array}{l}\mathrm{BMD}\left(\mathrm{g} / \mathrm{cm}^{3}, \text { mean } \pm \text { S.D.) }\right. \\
\text { (mean percent changes from baseline, } \%)\end{array}$} \\
\hline & Lumbar & Femoral neck & Lumbar & Femoral neck \\
\hline \multirow[t]{2}{*}{$\begin{array}{l}\text { Baseline } \\
12 \text { months }\end{array}$} & $\begin{array}{c}1.064 \pm 0.181 \\
1.024 \pm 0.174 *(-3.3 \%)\end{array}$ & $\begin{array}{c}0.731 \pm 0.106 \\
0.713 \pm 0.114 *(-3.3 \%)\end{array}$ & $\begin{array}{c}0.982 \pm 0.321 \\
1.011 \pm 0.322 *(+3.4 \% \dagger)\end{array}$ & $\begin{array}{c}0.671 \pm 0.094 \\
0.673 \pm 0.095(+0.43 \% \dagger)\end{array}$ \\
\hline & \multicolumn{4}{|c|}{ TRACP-5b (mU/dl, mean \pm S.D.) } \\
\hline $\begin{array}{l}\text { Baseline } \\
6 \text { months } \\
12 \text { months }\end{array}$ & \multicolumn{2}{|c|}{$\begin{array}{c}219.1 \pm 166.2 \mathrm{mU} / \mathrm{dl} \\
368.4 \pm 175.1 \mathrm{mU} / \mathrm{dl}^{*} \\
426.1 \pm 167.1 \mathrm{mU} / \mathrm{dl}^{*}\end{array}$} & $\begin{array}{c}328.8 \pm \\
399.2 \pm \\
198.9 \pm\end{array}$ & $\begin{array}{l}\mathrm{mU} / \mathrm{dl} \\
\mathrm{mU} / \mathrm{dl} \\
\mathrm{nU} / \mathrm{dl} *\end{array}$ \\
\hline 12 months & \multicolumn{4}{|c|}{ Pentosidine ( $\mu \mathrm{g} / \mathrm{ml}$, mean \pm S.D.) (mean percent change from baseline, $\%$ ) } \\
\hline $\begin{array}{l}\text { Baseline } \\
6 \text { months } \\
12 \text { months }\end{array}$ & $\begin{array}{r}0.07 \\
0.0950 \pm 0 \\
0.0986 \pm 0\end{array}$ & $\begin{array}{l}.024 \\
(+25.4 \%) \\
(+34.7 \%)\end{array}$ & $\begin{array}{r}0.10 \\
0.0882 \pm 0 \\
0.0859 \pm 0\end{array}$ & $\begin{array}{l}53 \\
4.35 \% \dagger) \\
4.94 \% \dagger)\end{array}$ \\
\hline
\end{tabular}

BMD, Bone mineral density; TRAP-5b, tartrate-resistant alkaline phosphatase 5b; S.D., standard deviation. ${ }^{*} p<0.05 v s$. baseline, ${ }^{\dagger} p<0.05 v s$. denosumab (-) group.

\section{Results}

All 46 patients received the luteinizing hormone-releasing hormone (LHRH)-antagonist degarelix. The median prostatespecific antigen (PSA) level at baseline was $11.0 \mathrm{ng} / \mathrm{ml}$, which declined to $0.44 \mathrm{ng} / \mathrm{ml}$ after 12 months of ADT treatment. There was no prostate carcinoma progression in the 46 cases at 12 months. There was a significant change in the BMD of the femoral neck between the group that did not receive denosumab (D-) and the one that received denosumab (D+) group at baseline $\left(0.731 \mathrm{~g} / \mathrm{cm}^{3}\right.$ vs. $0.671 \mathrm{~g} / \mathrm{cm}^{3}$, respectively; $p=0.044$ ).

$B M D$. Denosumab was associated with an increased BMD at the lumbar spine and femoral neck (Table II). In the D+ group, BMD at the lumbar spine was increased by $6.7 \%$ compared with the D- group at 12 months $(+3.4 \%$ vs. $-3.3 \%$, respectively; $p<0.001)$. The BMD at the femoral neck was increased by $3.7 \%$ in the D+ group compared with the Dgroup at 12 months $(+0.43 \%$ vs. $-3.3 \%$, respectively; $p=0.007)$. In the D+ group, the BMD of the lumbar spine was increased significantly at 12 months compared with baseline (baseline, $0.981 \mathrm{~g} / \mathrm{cm}^{3} ; 12$ months, $1.011 \mathrm{~g} / \mathrm{cm}^{3}, p=0.013$ ). However, there was no significant increase at the femoral neck (baseline, $0.671 \mathrm{~g} / \mathrm{cm}^{3} ; 12$ months, $0.673 \mathrm{~g} / \mathrm{cm}^{3}$; $p=0.755)$. In the D- group, the BMD of the lumbar spine and femoral neck was decreased significantly at 12 months compared to baseline (lumbar: baseline, $1.064 \mathrm{~g} / \mathrm{cm}^{3}$ and 12 months, $1.024 \mathrm{~g} / \mathrm{cm}^{3}, p<0.001$; femoral neck: baseline, 0.731 $\mathrm{g} / \mathrm{cm}^{3}$ and 12 months, $\left.0.713 \mathrm{~g} / \mathrm{cm}^{3} ; p<0.001\right)$.

Changes in bone turnover and quality markers. Table II lists the changes in bone turnover and quality markers. After 12 months of treatment with denosumab, the mean TRACP-5b levels decreased significantly in the D+ group from baseline (328.8 mU/dl vs. $198.9 \mathrm{mU} / \mathrm{dl}, p<0.05)$. In contrast, the mean TRACP-5b levels in the D- group increased significantly between baseline and 6 months $(219.1 \mathrm{mU} / \mathrm{dl}$ to $368.4 \mathrm{mU} / \mathrm{dl}$ $p<0.05)$ and between baseline and 12 months $(219.1 \mathrm{mU} / \mathrm{dl}$ to $426.1 \mathrm{mU} / \mathrm{dl} p<0.05)$. The mean serum levels of pentosidine in the D+ group decreased between baseline and 12 months, but not significantly $(0.1059 \mu \mathrm{g} / \mathrm{ml}$ to $0.0859 \mu \mathrm{g} / \mathrm{ml}, p=0.168)$. In contrast, the serum pentosidine levels increased significantly in the D- group (from $0.0798 \mu \mathrm{g} / \mathrm{ml}$ at baseline to $0.0986 \mu \mathrm{g} / \mathrm{ml}$ at 12 months, $p=0.023)$. When the percent change was examined, serum pentosidine levels were decreased by $4.9 \%$ in the D+ group compared with the Dgroup at 12 months $(-4.94 \% v s .+34.7 \%, p<0.001)$.

\section{Discussion}

In this study of men receiving ADT for PCa, patients who also received denosumab for 12 months experienced a significant increase in BMD at the lumbar spine and femoral 
neck compared to patients who did not receive denosumab. A significant decline in the levels of the bone turnover marker TRACP-5b and the bone quality marker pentosidine was observed in patients receiving denosumab compared to patients who did not receive denosumab.

Smith et al. have reported many effects of denosumab administration in PCa patients receiving ADT. For example, denosumab significantly increased BMD and decreased the incidence of new vertebral fractures among men receiving ADT for non-metastatic PCa (12). The current study found a similar percent change in BMD at 12 months. Smith et al. also reported that the levels of bone turnover markers declined (12). The current study confirmed these results by measuring the change in TRACP-5b levels. Inhibiting osteoclast activity with denosumab prevented a decrease in bone density and reduced levels of bone turnover markers, such as TRACP-5b, thus reflecting a decrease in osteoclast activity. Therefore, denosumab plays a major role in the bone management of PCa patients treated with ADT and functions by preventing a reduction in BMD (14).

Recent research has reported that bone quality is an important factor determining bone strength, independent of BMD (15). The proposed determinants of bone quality are the accumulation of micro-damage and the formation of collagen cross-links (18). Both of these processes are regulated by cellular activities and tissue turnover rate (15). Impaired enzymatic cross-linking and/or increased nonenzymatic cross-links in bone collagen have been proposed as determinants of impaired bone mechanical properties during aging, osteoporosis and diabetes mellitus (19). Reduced bone turnover allows the formation of additional collagen cross-links via non-enzymatic means, resulting in the accumulation of non-enzymatic advanced glycation endproducts (AGEs) in bone tissue (20). Bone collagen glycation allows micro-damage in bones to spread more easily, thereby increasing the total crack of surface density and making bone tissue more brittle and more likely to fracture (21). Pentosidine, one of several AGEs' cross-links, has been quantified in bone and serum (22). Its accumulation is associated with age-related degradation in the mechanical properties of bone $(17,23)$. Pentosidine levels are higher in the bones of patients with femoral neck fractures compared with age-matched controls $(24,25)$. Serum pentosidine concentrations were positively correlated with the radiographic severity of lumbar spondylosis in a crosssectional study involving Japanese subjects (26). Higher urine pentosidine levels represent a risk factor for fracture in older adults with diabetes and may also account, in part, for the reduced bone strength observed in type 2 diabetes (27). Yamamoto et al. suggested that serum pentosidine levels may be associated with prevalent vertebral fractures in postmenopausal women with type 2 diabetes and serum pentosidine might reflect bone quality (28). Vaculik et al. reported that patients with hip fractures had higher serum and bone pentosidine concentrations than those with advanced-stage hip osteoarthritis. Therefore, they suggested that serum pentosidine is a potential biomarker for identifying subjects with impaired bone quality and strength (29). Together, these findings suggest a correlation between the concentration of serum, bone or urine pentosidine and an increased risk of fracture.

This study had several limitations. First, the investigated cohort of patients was small, meaning that this research has to be expanded using a larger study population. Second, the D+ group contained patients who received different doses of denosumab. However, when we analyzed the percent change in BMD, we observed similar trends between TRACP-5b and pentosidine, in patients treated by denosumab without metastases $(n=12)$ and patients without denosumab treatment (data not shown). Third, since this is a retrospective study, there is a possibility that treatment intervention by denosumab might have affected the patients' lifestyle, behavior and metabolism. It may be that the changes of patients' lifestyle, behavior and metabolism indirectly influenced the dynamics of pentosidine.

In summary, the current study demonstrated that serum pentosidine increased significantly during 12 months in $\mathrm{PCa}$ patients undergoing ADT. Additionally, denosumab increased BMD and inhibited bone quality markers, such as serum pentosidine as compared to patients who never took denosumab.

\section{Conflicts of Interest}

Yoshiyuki Miyazawa, Takahiro Syuto, Yoshitaka Sekine, Masashi Nomura, Hidekazu Koike, Hiroshi Matsui, Yasuhiro Shibata and Kazuto Ito declare that there are no conflicts of interest that could be perceived as prejudicing the impartiality of the research reported. Kazuhiro Suzuki is a recipient of research grants and honoraria from Daiichi-Sankyo Co. Ltd.

\section{Acknowledgements}

None.

\section{References}

1 Ito K: Prostate cancer in Asian man. Nat Rev Urol 11: 197-212, 2014.

2 NCCN guidelines Ver 3. 2016 Prostate Cancer.

3 Sharifi N, Gulley JL and Dahut WL: Androgen deprivation therapy for prostate cancer. JAMA 294: 238-244, 2005.

4 Bolla M, Collette L, Blank L, Warde P, Dubois JB, Mirimanoff RO, Storme G, Bernier J, Kuten A, Sternberg C, Mattelaer J, Torecilla JL, Pfeffer JR, Cutajar CL, Zurlo A and Pierart M: Long-term results with immediate androgen suppression and external irradiation in patients with locally advanced prostate cancer (an EORTC study): A phase III randomised trial. Lancet 360: 103-108, 2002. 
5 Falahati-Nini A, Riggs BL, Atkinson EJ, O’Fallon WM, Eastell $\mathrm{R}$ and Khosla S: Relative contributions of testosterone and estrogen in regulating bone resorption and formation in normal elderly men. J Clin Invest 106: 1553-1560, 2000.

6 Shahinian VB, Kuo YF, Freeman JL and Goodwin JS: Risk of fracture after androgen deprivation for prostate cancer. N Engl J Med 352: 154-164, 2005.

7 Smith MR, Lee WC, Brandman J, Wang Q, Botteman M and Pashos CL: Gonadotropin-releasing hormone agonists and fracture risk: A claims-based cohort study of men with nonmetastatic prostate cancer. J Clin Oncol 23: 7897-7903, 2005.

8 Coleman RE: Clinical features of metastatic bone disease and risk of skeletal morbidity. Clin Cancer Res 12: 6243-6249, 2006.

9 Coleman RE: Skeletal complications of malignancy. Cancer Suppl 80: 1588-1594, 1997.

10 Smith MR, Eastham J, Gleason DM, Shasha D, Tchekmedyian $\mathrm{S}$ and Zinner N: Randomized controlled trial of zoledronic acid to prevent bone loss in men receiving androgen deprivation therapy for non-metastatic prostate cancer. J Urol 169: 20082012, 2003.

11 Smith MR, Malkowicz SB, Chu F, Price D, Sieber P, Barnette KG, Rodriguez D and Steiner MS: Toremifene increases bone mineral density in men receiving androgen deprivation therapy for prostate cancer: Interim analysis of a multicenter phase 3 clinical study. J Urol 179: 152-155, 2008.

12 Smith MR, Egerdie B, Hernández Toriz N, Feldman R, Tammela TJ, Saad F, Heracek J, Szwedowski M, Ke C, Kupic A, Leder BZ and Goessl C: Denosumab in men receiving androgen-deprivation therapy for prostate cancer. N Engl J Med 361: 745-755, 2009.

13 Smith MR, Coleman RE, Klotz L, Pittman K, Milecki P, Ng S, Chi KN, Balakumaran A, Wei R, Wang H, Braun A and Fizzazi $\mathrm{K}$ : Denosumab for the prevention of skeletal complications in metastatic castration-resistant prostate cancer: Comparison of skeletal-related events and symptomatic skeletal events. Ann Oncol 26: 368-374, 2009.

14 Smith MR, Saad F, Egerdie B, Sieber P, Tammela TJ, Leder BZ, $\mathrm{Ke} \mathrm{C}$ and Goessl C: Denosumab and changes in bone turnover markers during androgen deprivation therapy for prostate cancer. J Bone Miner Res 26: 2827-2833, 2011.

15 Seeman E and Delmas PD: Bone quality--The material and structural basis of bone strength and fragility. N Engl J Med 354: 2250-2261, 2006.

16 Saito M and Marumo K: Collagen cross-links as a determinant of bone quality: A possible explanation for bone fragility in aging, osteoporosis, and diabetes mellitus. Osteoporos Int 21: 195-214, 2010.

17 Wang X, Shen X, Li X and Agrawal M: Age-related changes in the collagen network and toughness of bone. Bone 31: 1-7, 2002.

18 Leali PT, Muresu F, Melis A, Ruggiu A, Zachos A and Doria C: Skeletal fragility definition. Clin Cases Min Bone Metab 8: 1113, 2011.
19 Saito M, Kida Y, Kato S and Marumo K: Diabetes, collagen, and bone quality. Curr Osteoporos Rep 12: 181-188, 2014.

20 Bailey AJ, Paul RG and Knott L: Mechanisms of maturation and ageing of collagen. Mech Ageing Dev 106: 1-56, 1998.

21 Vashishth D: Advanced glycation end-products and bone fractures. IBMS Bonekey 6: 268-278, 2009.

22 Odetti P, Rossi S, Monacelli F, Poggi A,Cirnigliaro M, Federici $\mathrm{M}$ and Federici A: Advanced glycation end products and bone loss during aging. Ann NY Acad Sci 1043: 710-717, 2005.

23 Hernandez CJ, Tang SY, Baumbach BM, Hwu PB, Sakke AN, van den Ham F, DeGroot J, Bank RA and Keaveny TM: Trabecular microfracture and the influence of pyridinium and non-enzymatic glycation-mediated collagen cross-links. Bone 37: 825-832, 2005.

24 Saito M, Fujii K, Soshi S and Tanaka T: Reductions in degree of mineralization and enzymatic collagen cross-links and increases in glycation-induced pentosidine in the femoral neck cortex in cases of femoral neck fracture. Osteoporos Int 17: 986-995, 2006.

25 Saito M, Fujii K and Marumo K: Degree of mineralizationrelated collagen crosslinking in the femoral neck cancellous bone in cases of hip fracture and controls. Calcif Tissue Int 79: 160-168, 2006.

26 Chiba D, Wada K, Tanaka T, Kumagai G, Sasaki E, Takahashi I, Nakaji S and Ishibashi Y: Serum pentosidine concentration is associated with radiographic severity of lumbar spondylosis in a general Japanese population. J Bone Miner Metab 35(1): 65$72,2017$.

27 Schwartz AV, Garnero P, Hillier TA, Sellmeyer DE, Stromeyer ES, Feingold KR, Resnik HE, Tylavsky FA, Black DM, Cummings SR, Harris TB and Bauer DC: Pentosidine and increased fracture risk in older adults with type 2 diabetes. J Clin Endocrinol Metab 94: 2380-2386, 2009.

28 Yamamoto M, Yamaguchi T, Yamauchi M, Yano S and Sugimoto T: Serum pentosidine levels are positively associated with the presence of vertebral fractures in postmenopausal women with type 2 diabetes. J Clin Endocrinol Metab 93: 1013-1019, 2008.

29 Vaculík J, Braun M, Dungl P, Pavelka K and StepanJJ: Serum and bone pentosidine in patients with low impact hip fractures and in patients with advanced osteoarthritis. BMC Musculoskelet Disord 17: 308, 2016.
Received May 25, 2017

Revised June 9, 2017

Accepted June 12, 2017 